\title{
NOTAS SOBRE A EDUCAÇÃO PARAENSE NA SEGUNDA REPÚBLICA
}

\author{
Alberto Damasceno \\ Universidade Federal do Pará - UFPA
}

\begin{abstract}
RESUMO
A partir da intervenção política levada a efeito a partir da Revolução de 30 no Estado do Pará sob a liderança de Magalhães Barata, é possível identificar um importante avanço no que se refere à oferta educacional nos seis primeiros anos do governo revolucionário, tanto quantitativamente como em termos de inovação pedagógica, a exemplo do uso do rádio e da implementação da Escola Nova. O aumento significativo das matrículas e da quantidade de estabelecimentos escolares não deixam dúvidas quanto à preocupação com a expansão das oportunidades de escolarização por parte do governo revolucionário. Entretanto, nossos estudos deixaram patente que esse processo desencadeado pela "nova ordem" republicana não apresentou em todos os momentos e lugares a marca da transformação social.

Palavras-chave: Educação; Segunda República; Pará.
\end{abstract}

\section{NOTES ON PARAENSE EDUCATION IN THE SECOND REPUBLIC}

\begin{abstract}
From the political intervention carried out from the Revolution of 30 in Pará State under the leadership of Magalhães Barata it's possible to identify an important advance concerning to educational provision in the first six years of the revolutionary government, both quantitatively and in terms of pedagogical innovation, such as the use of radio and the implementation of the New School. The significant increase in enrollment and in the number of schools clearly represents worries by the revolutionary government about the expansion of educational opportunities. However, our study concluded that this process initiated by Republican "new order" did not show at all times and places the mark of social transformation.
\end{abstract}

Keywords: Education; Second Republic; Pará.

\section{A AMPLIAÇÃO DAS MATRÍCULAS}

Quando toma posse do governo revolucionário, Getúlio Vargas apresenta em conjunto com seus colaboradores um programa de reconstrução nacional que incluía a "difusão intensa do ensino público, principalmente técnico-profissional, estabelecendo para isso um sistema de estímulos e colaboração direta com os Estados" (VARGAS apud PAIVA, 1987, p. 113).

Referindo-se ao período que então se inicia, Paiva (1987, p. 115) atesta que:

Uma característica se mantém constante: o interesse pela educação rural e pelo ensino técnico-profissional, cuja ênfase se implicaria por serem percebidos como o aspecto educacional da estratégia governamental para a solução da questão social. 
Citando Lourenço Filho a autora assevera que graças aos esforços locais "a matrícula nos Estados crescera bastante nos últimos anos da Primeira República e triplicara durante a Segunda República" (PAIVA, 1987, p. 115).

No Pará essa realidade se repete. Na Tabela 1 é possível visualizar, pelo menos até 1933, o importante crescimento no número de estabelecimentos e matrículas em nosso Estado.

Tabela 1 - Matrículas nos estabelecimentos públicos no Pará (1929-1936).

\begin{tabular}{l|l|l|l|ll|c}
\hline \multicolumn{1}{c|}{ ANOS } & MASC. & FEM. & TOTAL & \% RELATIVA & ACUMULADA \\
\hline 29 & & & 20.765 & $100 \%$ & $100 \%$ \\
\hline 30 & & & 20.543 & $-222-1 \%$ & $99 \%$ \\
\hline 31 & 23.246 & 17.863 & 41.109 & $+20556 \quad 100 \%$ & $199 \%$ \\
\hline 32 & 25.362 & 19.667 & 45.029 & +3920 & $9,5 \%$ & $208,5 \%$ \\
\hline 33 & 26.900 & 21.680 & 48.580 & $+3551 \quad 7,8 \%$ & $216,3 \%$ \\
\hline 34 & 32.102 & 25.240 & 57.342 & $+8762 \quad 18 \%$ & $234,3 \%$ \\
\hline até maio de 36 & 33.100 & 27.009 & 60.169 & $+2827 \quad 4,9 \%$ & $239,2 \%$ \\
\hline
\end{tabular}

Fonte: De 29 a 33: Jornal O ESTADO DO PARÁ (09-ABR-1934, p. 35). De 34 a 36: PARÁ: 1936-A.

Pode-se observar um significativo aumento das matrículas nos estabelecimentos públicos nos seis primeiros anos do governo revolucionário. De 1929 a maio de 1936 as matrículas cresceram cerca de $242 \%$, o que caracteriza, de fato, uma maior preocupação com a expansão das oportunidades de escolarização.

Entretanto, há que se dizer que tal crescimento deveu-se fundamentalmente aos esforços estaduais, pois:

Do financiamento federal beneficiaram-se os Estados do Sul, onde o problema das 'escolas estrangeiras' nas zonas de imigração determinou a nacionalização das escolas; os demais Estados contavam com seus próprios recursos além de alguma aplicação municipal (PAIVA, 1987, p. 115).

Refletindo, com características próprias, a preocupação que o novo regime tinha com a educação a nível nacional, o governo revolucionário no Pará manifestava, assim, afinada sincronia com as decisões relativas ao aspecto quantitativo da instrução. Tal interesse, segundo Paiva (1987, p. 114) dava-se:

Não mais com a preocupação de ampliar as bases de representação política através do voto (como na década de 10), pois o regime não permite a consulta eleitoral, mas com a intenção de utilizar a educação como veículo de difusão ideológica, através de conteúdo cívico e moral, para a sedimentação da nova política.

No Quadro 1 se pode avaliar a consonância do crescimento das matrículas no Pará com o mesmo fenômeno a nível nacional de 1920 a 1940. 
Quadro 1 - Crescimento de matrículas no Pará (1920 - 1940).

\begin{tabular}{|c|c|c|}
\hline ANOS & TOTAL DE MATRÍCULAS & CRESCIMENTO \\
\hline 1920 & 1.142 .702 & $100,00 \%$ \\
1940 & 3.328 .471 & $291,28 \%$ \\
\hline
\end{tabular}

Fonte: Romanelli, 1978.

\section{O AVANÇO PARA O INTERIOR}

Quanto à educação rural se observa especial esforço no sentido de garantir a expansão das oportunidades e escolarização no interior. Nos jornais da época é comum encontrar-se referências às obras que o governo estadual - na pessoa do Interventor Federal Joaquim Magalhães Barata - vinha desenvolvendo neste sentido:

A instrucção publica do Pará, tem atingido, nos dias presentes, a um grau de desenvolvimento acima de toda expectativa. É sobremodo consolar o movimento que, nesse sentido, se opera em todo o Estado. As escolas se multiplicam, as matrículas se elevam, o aparelhamento pedagógico melhora e aumenta, sendo extraordinária a remessa de material escolar para o interior pelo almoxarifado da derectoria da Educação e Ensino Público (O ESTADO DO PARÁ: 26-5-1933, p. 2).

Notícias sobre realizações educacionais em municípios do interior são inúmeras, a ponto de, em uma só edição do jornal "Estado do Pará" constarem ações do regime revolucionário em Acará, Santo Antonio de Aruans, Óbidos, Abaeté, Curuçá, Irituia, Igarapé-Miri, Gurupá e Marapanim (O ESTADO DO PARÁ: 9-4-1934, p. 14, 16, 18, 20 , 22 e 24).

Em 1934, ainda preocupado com a necessidade de escolas nas zonas rurais e urbanas o governo cria uma comissão de planejamento educacional visando o atendimento à demanda:

Atendendo no que solicitou o titular da pasta de educação e saúde pública, o director baixou portaria nomeando os professores Dr. Honorato de Castro Figueira, Padre José Cupertino Contente, Maria Antonieta Serra Freira Pontes, Maria Ribeiro da Costa Aguiar, Placida Alves Cardoso de Oliveira Pantoja, Lana Martins de Oliveira e Emilia Henderson Loureiro, para constituirem a comissão que tem de apresentar sugestões sobre as necessidades educacionais das zonas ruraes e urbanas do ensino elementar, profissional e secundario (O ESTADO DO PARÁ: 18-10-1934).

Outro bom demonstrativo do interesse governamental pelo interior do Estado é o Quadro 2, que ilustra a diferença entre o crescimento das matrículas na capital e nos outros municípios. 
Quadro 2 - Mapa: comparativo da matricula e da frequência média dos estabelecimentos de ensino públicos estaduais, nos anos de 1934 a $1936^{1}$.

\begin{tabular}{|c|c|c|c|c|c|c|}
\hline \multirow{3}{*}{ LOCALIDADES } & \multicolumn{6}{|c|}{ E M 1934} \\
\hline & \multicolumn{3}{|c|}{ MATRICULA GERAL } & \multicolumn{3}{|c|}{ FREQUENCIA MEDIA } \\
\hline & MASC. & FEMININO & TOTAL & MASC. & FEMININO & TOTAL \\
\hline CAPITAL & 6.300 & 5.996 & 21,44 & 3.630 & 4.065 & 7.695 \\
\hline INTERIOR & 25.802 & 19.244 & 78,55 & 15.960 & 12.331 & 28.291 \\
\hline \multirow[t]{2}{*}{ TOTAL ................ } & 32.102 & 25.240 & 57.342 & 19.540 & 16.396 & 35.986 \\
\hline & \multicolumn{6}{|c|}{ E M 1935} \\
\hline \multirow[t]{2}{*}{ LOCALIDADES } & \multicolumn{3}{|c|}{ MATRICULA GERAL } & \multicolumn{3}{|c|}{ FREQUENCIA MEDIA } \\
\hline & MASC. & FEMININO & TOTAL & MASC. & FEMININO & TOTAL \\
\hline CAPITAL. & 6.668 & 6.583 & 22,02 & 5.392 & 4.304 & 9.696 \\
\hline INTERIOR .. & 26.492 & 20.126 & 77,97 & 23.618 & 14.877 & 38.495 \\
\hline \multirow[t]{2}{*}{ TOTAL ................ } & 33.160 & 27.009 & 60.169 & 29.010 & 19.181 & 48.191 \\
\hline & \multicolumn{6}{|c|}{ ATÉ 31 DE MAIO DE 1936} \\
\hline \multirow[t]{2}{*}{\begin{tabular}{|l} 
LOCALIDADES \\
\end{tabular}} & \multicolumn{3}{|c|}{ MATRICULA GERAL } & \multicolumn{3}{|c|}{ FREQUENCIA MEDIA } \\
\hline & \begin{tabular}{|l|} 
MASC. \\
\end{tabular} & FEMININO & TOTAL & MASC. & FEMININO & TOTAL \\
\hline CAPITAL & 5.793 & 5.945 & 18.99 & 4.169 & 4.416 & 8.585 \\
\hline INTERIOR & 28.183 & 21.863 & 81.00 & 25.304 & 20.817 & 46.121 \\
\hline TOTAL …............... & 33.976 & 27.808 & 61.784 & 29.473 & 25.233 & 54.706 \\
\hline
\end{tabular}

Fonte: PARÁ: 1936-A, pág. 101.

Como se pode perceber, em 1934 e 1935, as matrículas na capital ainda cresciam mais, atingindo um aumento percentual de 7,8\%, enquanto no interior este era de $4,2 \%$. No entanto, de 1935 até maio de 1936, as matrículas na capital decresceram em 11,4\%, enquanto no interior a expansão foi de $6,6 \%$. No fim das contas contabiliza-se $10,8 \%$ de aumento das matrículas no interior enquanto na capital o resultado é negativo em 3,6\%.

Este é um bom indicador da direção que a política educacional na $2^{\mathrm{a}}$ República adotada no Pará, em consonância com as diretrizes emanadas do comando geral do governo revolucionário, na perspectiva de "invadir" as bases das oligarquias rurais através da implantação de políticas sociais nas áreas rurais.

Magalhães Barata percorreu inúmeras vezes todos os municípios do Estado, fato absolutamente novo, inusitado, o que lhe garantia também uma comovente solidariedade e o apoio incondicional que o confirmaria como grande líder, sua ambição maior. Em suas viagens, nunca deixou de levar medicamentos, alimentos, roupas, médicos, dentistas e até barbeiro. Para um Estado com as dimensões do Pará, onde as distâncias se contavam em dias, semanas de viagens exaustivas, só um indivíduo com energia extraordinária, messianicamente inclinado para o cumprimento do dever, em busca de uma afirmação carismática, poderia alcançar sucesso. E Magalhães Barata atingiu seus objetivos (RODRIGUES, 1979, p. 53).

Mesmo no governo posterior ao de Barata — o de Gama Malcher - intensificase a preocupação com as escolas rurais. Na sua mensagem ao Legislativo Malcher dedica extensa pauta referindo-se à necessidade de criação deste tipo de instituto.

Considerando que um dos mais importantes problemas economicos do Brasil é o da agricoltura, julgamos necessaria a creação de escolas ruraes, destinadas a dar ás populações do interior uma instrucção solida, porém 
compativel com o meio, orientando-as para a cultura racional e intensiva da terra, despertando-lhes o amor e o carinho pelos campos brasileiros, fontes inexgottaveis da riqueza do paiz, tão mal comprehendidas pelas populações ruraes, incultas e doentias, que mal orientadas sonham sempre trocal-os pela capital.

Creado e desenvolvido este amor pelo solo patrio, consideremos resolvido um dos nossos mais importantes problemas sociaes.

Aos professores ruraes, seria de inteira justiça, se as condições financeiras assim o permitissem, assegurar vencimentos equivalentes aos da capital.

Infelizmente, com a nova regulamentação da Escola Normal, foi necessario extinguir o Curso Normal Rural do Instituto Gentil Bittencourt, ficando a funccionar apenas o Curso Domestico do Orphanato Antonio Lemos, craedo pelo Decreto $n^{\circ} 1.846$ de 3 de janeiro de 1936. Destina-se o alludido curso a formar professores ruraes, permittindo assim integrar a escola no ambiente proprio, nas zonas campestres. Crear apenas o curso não resolve o problema e necessario se torna ampliar e melhorar as installações do Curso Domestico, que consideramos obra de grande projecção social.

No anno findo, 9 foram as alumnas diplomadas pela Escola Normal Rural do Instituto Gentil Bittencourt e 6 pelo Orphanato Antonio Lemos. Destas professoras ruraes 4 já foram nomeadas para reger escolas no interior.

Seria conveniente que de futuro outras escolas ruraes fossem creadas nos mais populosos municipios do interior (PARÁ: 1936-A, p. 98-9).

\section{A UTILIZAÇÃO DO RÁDIO}

Uma das características mais importantes desse período é a utilização do meio de comunicação radiofônico visando sobretudo a educação rural. Esta, durante a década de 30, alia-se à:

Solução dos problemas sanitários e se anuncia para muitos como um possível caminho de contenção das correntes migratórias do campo para as cidades [...].

Continua na Segunda república o movimento em favor da educação popular através do rádio, iniciado nos anos 20. A defesa da rádioeducação havia sido incorporada pelos renovadores e já na Reforma do Distrito Federal em 1928 era prevista a criação de uma rádio-escola municipal (PAIVA, 1987, p. 119).

O governo paraense, sempre atento às iniciativas federais e de outros Estados procurou garantir esta aliança estratégica com o mais popular meio de comunicação social, utilizando-o de maneira competente na difusão de suas mensagens oficiais e extra-oficiais. Anos depois outra iniciativa corroboraria para a estreita ligação do rádio com a educação e, evidentemente, com a difusão ideológica da nova ordem política - no Pará.

No dia 26 de setembro de 1936 o então governador Gama Malcher sanciona a lei $\mathrm{n}^{\mathrm{o}} 34$ concedendo à Rádio Clube do Pará um auxílio de oitenta contos de réis para a construção de seu novo edifício social e para a montagem de suas instalações. Pelos termos desse convênio a Rádio Clube ficava obrigada a: 
a) Transmitir, diariamente, durante quinze minutos e independente de retribuição, palestras organizadas pela Diretoria Geral de Educação e Cultura.

b) Transmitir, diariamente, durante quinze minutos palestras organizadas pela Diretoria Geral de Saúde Pública.

c) Transmitir, diariamente, os noticiários dos atos oficiais do Governador do Estado.

d) Transmitir do recinto das sessões os trabalhos da Assembléia Legislativa.

$\S$ Único. Fica vedado à Rádio Clube do Pará ceder, a título gratuito ou oneroso, as suas instalações para a propaganda política ou eleitoral de qualquer partido. (PARÁ: 1936-B)

Em maio de 1937, no seu $3^{\circ}$ comunicado à Imprensa a diretoria regional da "Cruzada Nacional de Educação no Pará", divulga suas atividades realizadas durante o período de três semanas. Dentre as dez ações efetivadas, duas dizem respeito à Rádio Clube do Pará e são quase absurdas se considerado o paradoxo que encerram:

VI - Irradiação de palestras de propaganda da campanha de divulgação do A.B.C. pela estação PRC-5, Rádio Clube do Pará.

IX - Adiamento para próximos dias de várias palestras destinadas à Semana de Educação, prejudicada com a suspensão do funcionamento da estação PRC-5 Rádio Clube do Pará (O ESTADO DO PARÁ: 8-5-37, p. 2).

Ainda em junho em nova reunião a diretoria da "cruzada" agradece nova colaboração da "PRC-5" junto a seu movimento em prol da alfabetização:

A Rádio Clube do Pará, por gentileza de sua directoria, offereceu alguns minutos para que a directoria regional faça divulgação dos resultados da campanha financeira para manutenção e auxílio das escolas criadas pela Cruzada, o que será feito periodicamente, podendo todos ter conhecimento da evolução das propagandas (FOLHA DO NORTE: 28-61937, p. 3).

\section{A INFLUÊNCIA DA ESCOLA NOVA}

Jorge Nagle estabelece duas grandes fases da penetração do escolanovismo no Brasil. A primeira fase, "vai dos fins do período imperial até o final da segunda década deste século" (NAGLE, 1976, p. 239). O autor classifica essa fase como sendo de "antecedentes", seja quanto a "procedimentos, idéias ou princípios", seja quanto às condições para o seu desenvolvimento real.

Já na segunda fase, o que se vê é a difusão e as realizações. Compreendido na década de 20, "tenta-se, pela primeira vez, realizar o novo modo de estruturação das instituições escolares" (NAGLE, 1976, p. 241).

No Estado do Pará esta segunda fase desenvolve-se tardiamente, e, de certa forma, coincidindo com a eclosão da Revolução Liberal de 1930. O processo de expansão das redes escolares a nível estadual que se deu de forma intensiva a partir de então, deveu-se fundamentalmente aos esforços dos seus governos como já vimos. Todavia, há que se registrar que a preocupação com a qualidade não fôra esquecida, pois foram desenvolvidas 
"durante a Segunda República reformas qualitativas locais orientadas pelos renovadores" (PAIVA, 1987, p. 115).

Se for verdade que, pelo menos em sua origem, este regime recém-instaurado tinha profunda encarnação ideológica de tipo liberal é possível compreender os importantes avanços que o escolanovismo logrou consolidar na área educacional. Jorge Nagle argumenta que o liberalismo

Significou a quebra dos velhos quadros opressores do desenvolvimento da personalidade humana, a ruptura do sistema de obstáculos que impedia o desenvolvimento harmônico (porque "natural") da sociedade humana. Ao estabelecer a rotina do não-constrangimento nas diversas esferas da vida social - política, econômica, social e cultural - a doutrina liberal firmou, ao mesmo tempo, o princípio básico das liberdades. Dessa forma, não surpreendendo observar que o enraizamento da Escola Nova se tenha processado pouco depois do triunfo das idéias liberais; na verdade, o escolanovismo representou, ortodoxamente, o liberalismo no setor da escorização. Não foi casual, agora no caso brasileiro, o fato de que a mais ampla crítica à "escola tradicional" e as primeiras manifestações que denunciam a presença do novo ideário educacional partissem de um liberal, o Conselheiro Rui Barbosa; isso mostra, fundamentalmente, o início de um movimento educacional, que é expressão, antes de tudo, de movimentos sociais mais amplos (NAGLE, 1976, p. 241-242).

Esse foi o intento de Magalhães Barata ao pretender organizar a reforma da Escola Normal em Instituto de Educação. O Diretor Geral da Educação e Ensino Público, Genuíno Amazonas de Figueiredo promoveu, para tal, uma série de conferências pedagógicas a cargo dos educadores paraenses Guilherme de Azevedo Ribeiro, Antonio Nascimento, Paulo Eleutherio e Mariana Sarmanho. Os temas abordados constituíam-se em: Psicologia Educacional, Ensino de Desenho, História da Educação e Pedagogia Aplicada ${ }^{2}$. Pode-se depreender que esta, junto a outras iniciativas, revela a importância que era dada à compreensão pelo corpo docente em atuação, das novidades educacionais e pedagógicas em voga.

São inúmeras as medidas oficiais relativas ao aperfeiçoamento, ou, se quisermos, à "modernização" do processo pedagógico. Têm-se notícias de palestras pedagógicas cuja presença dos "Membros do magistério público" era obrigatória (O ESTADO DO PARÁ: 10-08-1933); da instalação de aparelhos de projeção para viabilizar o "cinema educativo" visando o "ensino intuitivo aos escolares dos grupos e escolas da capital e interior" (O ESTADO DO PARÁ; 22-8-1934, p. 2); da criação de aulas práticas sobre "jardino-cultural e horticultura" nos grupos escolares e em outros estabelecimentos, visando "A creação, a titulo de experiência, de uma curso de agronomia elementar, horticultura e jardinocultura, no Instituto Gentil Bittencourt, ás alumnas do curso normal rural" (O ESTADO DO PARÁ: $1 / 4 / 1933$, p. 2); ou de cursos de aperfeiçoamento que a isto visavam. Cito a seguir um trecho de matéria publicada em jornal da época que bem ilustra essa perspectiva: " $O$ Dr. Diretor de Educação acaba de publicar portaria, creando um 'curso propedêutico de aperfeiçoamento' a fim de o professorado público, refazendo e alargando estudos com efficiência praticar os methodos modernos de ensino" (O ESTADO DO PARÁ: 10-081933, p. 2).

Buscava-se articular - nem sempre com sucesso - a expansão quantitativa com a renovação qualitativa da educação no Estado. A crítica ao pouco que se fazia e o conteúdo 
das medidas podem ser exemplificadas nesta passagem que toma a "pedagogia moderna" como fulcro do desenvolvimento escolar:

Quem sabia o abandono a que estava relegado o ensino, no Pará, em quasi vinte annos de incurias administrativas, e o contempla agora nossa phase de verdadeiro soerguimento, nos moldes da pedagogia moderna, tanto quanto permittem as finanças do Estado, tomase de pasmo, indagando como em pouco tempo, em dois annos apenas, o governo revolucionário desta terra soube dar ao ensino a mais acertada diretriz $(\mathrm{O}$ ESTADO DO PARÁ: 26-5-1933, p. 2).

Comentando a visita de Barata a uma sala de alfabetização do Grupo Barão do Rio Branco - um dos mais conceituados de Belém, o Jornal Estado Do Pará apresenta uma breve incursão crítica sobre as mudanças pedagógicas então desenvolvidas no Estado:

Antigamente, nessa aula era ministrado o ensino do "a,b,c" e actualmente as creanças recebem a instrução pelos methodos da pedagogia moderna, ou sejam licções práticas.

A aula de hontem, por exemplo, foi referente ao cacau, a sua utilidade e applicação, estando a vista dos alumnos que ouviam com attenção a preleção, o fructo, a folha e o caule do cacaueiro, bem como o chocolate em pó, em paes e bons-bons, geleas, doces, etc, explicando a professora a utilidade da arvore, que deve ser protegida por todos, inclusive as creanças, porque produz uma fructa que serve de alimentação ao homem, sendo as diversas phases da prelecção orientadas com exibição daquelles elementos, principalmente os productos originários da fructa do cacaueiro.

Finda a aula, dois alumnos, um menino e uma menina offertam ao Sr. major interventor um ramalhete de flores naturaes, tendo $S$. exc. agradecido, beijando a mão dos dois petizes (O ESTADO DO PARÁ: 147-1934).

Outro exemplo pode ser visto em Palmira Lins de Carvalho, uma das maiores divulgadoras do pensamento escolanovista no Pará. Numa de suas palestras, sobre os novos métodos de ensino ministrados em suas classes no Grupo Barão do Rio Branco, chegou a fazer demonstrações práticas do processo pedagógico por ela utilizado. Este é o depoimento de um jornalista, acerca do que presenciou:

Observou-se o interesse da criança ante a nova aprendizagem, tendo diante de si a própria natureza. As crianças aprendem amar as arvores, a sua utilidade, o plantio de vários de nossos fructos e o emprego de cada um.

No próprio folguedo, nos jardins, as crianças têm o seu A,B,C.

Pela divisão de um fructo entre collegas, recebem a noção de contar a fracção. Enfim foi uma palestra de grande utilidade principalmente para todos aqueles que vêm o espírito infantil para educar, pondo-o a par da nossa própria natureza antes de tudo (O ESTADO DO PARÁ: 22-7-1934, p. 4).

No entanto, ao mesmo tempo em que imprimia visível estímulo ao desenvolvimento ensino paraense, Barata também cometia agressões à qualidade do 
mesmo, permitindo - a custa de interesses eleitorais - equívocos como a inclusão de professoras sem habilitação no quadro de pessoal docente das escolas públicas.

Ao conceder entrevista à "Folha do Norte" de 29 de fevereiro de 1936 o Diretor Geral de Educação e Cultura do Governo de José Malcher, Oswaldo Orico declarava dentre outras medidas - ter acabado:

Com as professoras leigas que a administração revolucionária havia infiltrado no magisterio da Capital, abrindo um precedente prejudicial ao interesse do ensino. Atribuiu-lhes no mecanismo escolar uma função puramente administrativa, sem ferir-lhes os direitos, como auxiliarsecretárias dos grupos e escolas isoladas. E chamou-se para as vagas que se abriram professoras diplomadas pela Escola Normal, com tirocínio no magistério (FOLHA DO NORTE, 22-9-1936).

Com efeito, é no Governo de Gama Malcher que se pode observar um maior grau de complexidade no que se refere às realizações baseadas na Escola Nova. Não mais de elogios fugidios, mas de adequação das instalações escolares às exigências dos novos métodos. Note-se que não passa despercebida pelo governador a necessidade de se manter a "pureza" da raça, o que demonstra que em nosso Estado, aspectos de um ideário racista que já se fazia presente.

A escola nova, revolucionando completamente os methodos de ensino, com o fito de tornal-o mais accessivel á intelligencia infantil, trouxe como consequencia a ampliação do apparelhamento didactico, tornando-o cada vez mais dispendioso.

$\mathrm{O}$ actual desenvolvimento da sciencia educacional exige não só installações perfeitas para o preparo intellectual do alumno, como também um sã assistencia moral e bem orientada educação physifica.

De facto, para que um estabelecimento de ensino possa corresponder á sua finalidade é necessario que o predio onde funccione preencha todos os requisitos exigidos pela hygiene escolar, afim de evitar a degenerescencia physica da raça. Além disso, é imprescindivel que seu corpo docente seja culto, dedicado, animado de um são patriotismo e tenha á sua disposição um apparelhamento escolar completo, de maneira a permittir que o ensino ministrado seja essencialmente pratico, intuitivo e attrahente, afim de despertar o interesse do alumno pela escola, actualmente encarada como um prolongamento do lar.

É por isso que, procurando corresponder á confiança publica, temos em vista dotar o Estado de tres estabelecimentos modelares, a serem construidos de acordo com os preceitos da pedagogia moderna. Estes predios escolares, com capacidade de 200 alumnos cada um, serão edificados de preferencia nos populosos bairros suburbanos da capital, habitados em sua maioria pela laboriosa classe operária.

O primeiro destes predios já está em construção à praça do Centenario e os dois outros serão iniciados brevemente nos bairros da pedreira e dos Jurunas (MENSAGEM, 1936-A, 96-7).

\section{EDUCAÇÃO SEXUAL E EDUCAÇÃO FEMININA: NOVAS EXPERIÊNCIAS}

Um tema importante ligado à qualidade da educação, senão a seu conteúdo e que apareceu fortemente durante o período estudado, fica por conta da educação sexual. Muito embora pareça ser uma preocupação recente - das últimas décadas - no Brasil a sexualidade 
era vista já em 1933 como uma dimensão da vida humana que precisava ser estudada, discutida e até "libertada".

O presidente do "Círculo Brasileiro de Educação Sexual", Dr. José de Albuquerque escrevia em artigo no jornal "Folha do Norte" sobre a "empolgação" que o tema causava e merecia:

A segunda metade do anno de 1933, no Brasil foi fortemente movimentada no terreno educacional, pelo grito de alarme dado por uma instituição que vinha de se fundar, para demonstrar a necessidade da educação sexual.

Tal instituição, O Círculo Brasileiro de Educação Sexual, encontrou logo de início a acolhida sincera de toda a Imprensa da Capital da República.

$\mathrm{Na}$ sede da Associação Brasileira de Empresa realizou-se uma sessão de installação e a posse de sua primeira directoria eleita.

Algumas destacadas figuras do jornalismo tomaram parte em seus trabalhos iniciaes emprestando-lhe a sua actividade e prestigio.

Dois orgãos da imprensa do Rio de Janeiro abriram incontinente inqueritos, entrevistando os mais representativos elementos não só da classe medica como das hostes pedagogicas sobre a questão que então empolgava a opinião pública - a educação sexual (FOLHA DO NORTE, 29-1-1934).

Continuando, ele contava das necessárias medidas de divulgação do tema por todos os rincões do país, assim como, da importância da imprensa no cumprimento dessa tarefa:

Uma empresa jornalística, a união brasileira de imprensa, com irradiação em todo o paiz, comprehendendo as salutares ideologias por que estava se batendo a nova instituição, entrou logo a remeter para os jornaes a ella filiados, que se elevam ao avultado numero de tresentos artigos e noticiaes, chamando a attenção da população de todo nosso vasto "hinterland", para esta notavel instituição e para o seu vastissimo programma.

Finalmente, a directoria do Circulo Brasileiro de Educação Sexual, num aparelho dirigido aos directores dos jornaes brasileiros do interior do paiz, conseguiu congregar 780 orgãos da nossa imprensa, a cada um dos quaes são remetidos, quinzenalmente, artigos sobre educação sexual, que são publicados com regularidades pela maioria dos mesmos logrando dessa forma a nossa campanha uma irradiação sem precedentes nos annaes de nossa historia (FOLHA DO NORTE, 29-1-1934).

O articulista finaliza o texto com uma convocação peremptória aos jornalistas em prol da superação da ignorância e preconceito que grassavam em torno do tema, caracterizando-os como verdadeiros "libertadores":

Este é o primeiro contacto que travo com os jornalistas de meu paiz em 1934 e espero que o meu apello encontrará echo em suas consciencias de homens livres, estando certo que tudo envidação para livrar o nosso povo da maior de quanta tyrannias o subjugam, que é a tyrannia sexual. 
Avante, jornalistas de meu paiz! caminha e sem desffalecimentos, quando o melhor de vossas energias em prol desta nobre causa, e tereis a recompensa de serdes apontado como os libertadores de um captiveiro moral, assim como os escravocratas de 88 , no Brasil, o foram de um captiveiro physico (FOLHA DO NORTE, 29-1-1934).

Outra modificação qualitativa, todavia processada timidamente, refere-se ao crescimento das matrículas do sexo feminino em relação ao total de matrículas nas escolas. O Quadro 3 demonstra o lento, mas gradual aumento da participação das mulheres no total de alunos matriculados nas escolas públicas no Estado do Pará de 1931 a maio de 1936.

Quadro 3 - Percentual de mulheres nas matrículas das escolas públicas no estado do Pará (1931 a maio de 1936).

\begin{tabular}{|c|c|}
\hline ANOS & $\%$ \\
\hline 1931 & $43,45 \%$ \\
\hline 1932 & $43,67 \%$ \\
\hline 1933 & $44,62 \%$ \\
\hline 1934 & $44,00 \%$ \\
\hline 1935 & $44,88 \%$ \\
\hline maio de 1936 & $45,00 \%$ \\
\hline
\end{tabular}

Fonte: De 31 a 33: O Estado do Pará: 9-4-1934, p. 35. De 34 a 36: PARÁ: 1936-A.

Além disso, há outro exemplo que é a preocupação com a formação técnica e científica das jovens que se dispusessem a assumir a profissão de mestras. Advirto que tal não se daria sem a "indispensável formação na fé católica". Solicitando credenciamento e autorização de funcionamento ao Conselho Nacional de Educação e Saúde Pública para o seu Instituto Superior de Educação, as conêgas de Santo Agostinho, conseguem significativo espaço na Grande Imprensa para divulgarem seu projeto educacional e pedagógico. Diz a matéria que:

São evidentes as vantagens sociaes para as jovens, a par de uma cultura scientifica, desejam conhecer a doutrina catholica relativa aos problemas pedagógicos, que hoje preocupam todos os educadores. Não se concebe, em nossos dias, uma professora desprovida de cultura scientifica $(\mathrm{O}$ ESTADO DO PARÁ: 11-7-1934 - Secção Feminina).

A matéria continua dizendo que os cursos oferecidos pelo Instituto:

São desenvolvidos por professores competentes para ministrar às alumnas uma instrucção, tão completa quanto possível, sem fugir à doutrina catholica. É possivel a uma jovem professora enfrentar todos os problemas pedagogicos, quaesquer que elles sejam, com largueza de vistas e segurança de soluções, à luz da mais moderna e apurada sciencia, sem 0sentir diminuida a sua fé nas verdades christãs (O ESTADO DO PARÁ: 11-7-1934).

As disciplinas ali desenvolvidas consistiriam em "philosophia pedagógica, organização de ensino secundário, estatisticas, latim, literatura de lingua portugueza, geographia e história da civilização e sociologia, litteratura francesa, ingleza e allemã" (O ESTADO DO PARÁ: 11-7-1934). 


\section{CONSIDERAÇÕES FINAIS}

Durante esse período no Estado do Pará, o que se observa é que realmente há um aumento significativo das iniciativas governamentais no sentido da criação de oportunidades de educação formal. $\mathrm{O}$ avanço da escolarização para os municípios do interior do Estado, juntamente com a utilização do rádio como forma de apoio representaram iniciativas exitosas.

A criação da escola normal foi outra medida governamental que demonstra, mesmo que relativamente, a importância que a Revolução dava à formação de professores, para além da adoção da Escola Nova como paradigma pedagógico e educacional.

Quanto à educação destinada às mulheres, as ações desencadeadas evidentemente não significam uma transformação nas relações entre homens e mulheres, sobretudo considerando-se a forte tradição machista das sociedades brasileiras e paraenses. À mulher continuou a caber um papel secundário nas atividades culturais e políticas. Entretanto, como em outros aspectos a Segunda República não deixou de apresentar avanços positivos no movimento global em emancipação do sexo feminino.

É preciso que se diga, todavia, que a modernização do ensino promovida pelo movimento revolucionário em tela não tinha em todos os momentos e lugares a marca da transformação social. O estudo do caso paraense, corrobora a afirmação de Buffa e Nosella quando estes dizem que:

Toda educação nova e os próprios métodos ativos não constituem, neste século, um campo filosófico orgânico e autônomo, sendo antes uma filosofia educacional heterogênea onde se mesclam preocupações, teses, bandeiras, concepções tanto de natureza democrático-liberal quanto de caráter socialista. Porém, esse todo heterogêneo, sobretudo pela concepção desenvolvimentista da história contemporânea que pressupõe, não consegue ultrapassar os limites do idealismo (BUFFA; NOSELLA, 1992, p. 62).

No Estado do Pará pareceu-nos ficar patente do forte vínculo que tal processo manteve com a "manutenção da nova ordem" não atingindo em nenhum momento outro campo teórico, político e ideológico que não fosse aquele permitido pelas novas oligarquias encrustadas no poder estadual.

\section{REFERÊNCIAS}

A Escola Normal e o Ensino Moderno. O ESTADO DO PARÁ: Belém, 26-5-1933. p. 2.

ALBUQUERQUE. Educação sexual e os jornalistas brasileiros. FOLHA DO NORTE: 2901-1934.

BUFFA, Ester e NOSELLA, Paolo. A educação negada. São Paulo: Cortez, 1992.

CONCURSOS na Escola Normal. O Estado do Pará: Belém, 08-05-1937, p.2.

FOLHA do Norte, 29 de Janeiro de 1934.

FOLHA do Norte, 29 de Fevereiro de 1936.

FOLHA do Norte, 28 de Junho de 1937. 
INSTRUCÇÃO Pública. O Estado do Pará: Belém, 09-04-1934. p, 14. . O Estado do Pará: Belém, 09-04-1934. p, 16. . O Estado do Pará: Belém, 09-04-1934. p, 18. . O Estado do Pará: Belém, 09-04-1934. p, 20. . O Estado do Pará: Belém, 09-04-1934. p, 22. . O Estado do Pará: Belém, 09-04-1934. p, 24.

Movimento em prol da alfabetização. FOLHA DO NORTE. Belém, 28-06-1937, p.3.

NAGLE, J. Educação e sociedade na primeira república. São Paulo: EPU, 1976.

O ESTADO DO PARÁ, 14 de Maio de 1933.

O ESTADO DO PARÁ, 26 de Maio de 1933.

O ESTADO DO PARÁ, 10 de Agosto de 1933.

O ESTADO DO PARÁ, 9 de Abril de 1934.

O ESTADO DO PARÁ, 11 de Julho de 1934.

O ESTADO DO PARÁ, 14 de Julho de 1934.

O ESTADO DO PARÁ, 22 de Julho de 1934.

O ESTADO DO PARÁ, 22 de Agosto de 1934.

O ESTADO DO PARÁ, 18 de Outubro de 1934.

O ESTADO DO PARÁ, 8 de Maio de 1937.

PARÁ. Mensagem à Assembléia Legislativa: 1936-A.

PARÁ. Lei no 34, de 26 de Setembro de 1936: 1936-B.

PAIVA, V. Educação popular e educação de adultos. 5. ed. São Paulo: Loyola, 1987.

RODRIGUES, D. S. S. Pará/1935: um estudo sobre liderança e conflito. 124 f. 1979. Dissertação (Mestrado em Sociologia) - Universidade Cândido Mendes, Instituto Universitário de Pesquisas do Rio de Janeiro, Rio de Janeiro, 1979.

ROMANELLI, O. O. História da educação no Brasil. 9. ed. Petrópolis: Vozes, 1987.

${ }^{1}$ Os dados relativos ao ano de 1936 correspondem apenas ao período de 15 de janeiro a 31 de Maio.

2 O ESTADO DO PARÁ: 14-5-1933, p. 2.

Recebido: mai/15 Aprovado: jun/15 